\title{
Consolidation of Nanoscale Iron Powders
}

Z. Livne and A. Munitz Nuclear Research Center Negev Beer-Sheva, Israel

\section{J. C. Rawers}

U.S. Dept. of Energy

Albany, OR 97321

\section{R. J. Fields}

Metallurgy Division

NIST

Gaithersburg, MD 20899

QC

100

.456

N0.5990 



\section{Consolidation of Nanoscale Iron Powders}

Z. Livne and A. Munitz Nuclear Research Center Negev Beer-Sheva, Israel

\section{J. C. Rawers}

U.S. Dept. of Energy

Albany, OR 97321

\section{R. J. Fields}

Metallurgy Division

NIST

Gaithersburg, MD 20899

March 27, 1997

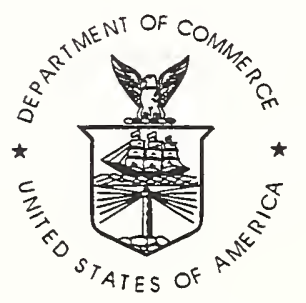

U.S. DEPARTMENT OF COMMERCE William M. Daley, Secretary

TECHNOLOGY ADMINISTRATION

Gary Bachula, Acting Under Secretary for Technology

NATIONAL INSTITUTE OF STANDARDS

AND TECHNOLOGY

Robert E. Hebner, Acting Director 



\title{
Consolidation of Nanoscale Iron Powders
}

\author{
Z. Livne', A. Munitz ${ }^{1}$, J. C. Rawers², and R. J. Fields \\ Metallurgy Division, NIST
}

\section{Abstract}

The consolidation behavior of two types of nanoscale iron powders, vacuum condensed (nanograins in nanoparticles) and ball-milled (nanograins in microparticles) was studied. For comparison, the consolidation of two microscale powders, atomized and ground, was also characterized. Consolidation techniques investigated were cold closed die compaction, cold isostatic pressing (CIPing), and, after CIPing, sintering or hot isostatic pressing (HIPing). The mechanical properties, density, and microstructure of the resulting compacts were found to depend on the type of powder, and its consolidation history. Significant differences in behavior were found between the microscale and nanoscale powders. An additional reason, besides the dissimilarity in grain size, for these differences was the fact that the two nanograin powders contained significant amounts of oxygen which ultimately resulted in a distinctly two phase bulk microstructure. The vacuum condensed powder achieved satisfactory green strength on CIPing and high hardness $\left(440 \mathrm{H}_{V}\right.$ - Vickers hardness) on low temperature sintering. While not necessary for complete consolidation, HIPing at $500{ }^{\circ} \mathrm{C}$ was found to be beneficial and compacts of this powder were found to have a hardness of $680 \mathrm{H}_{V}$ and a high compressive yield strength (1800 MPa). For ball-milled powders HIPing was found to be essential for effective consolidation. For example, the ball-milled material, which remained friable after CIPing and sintering at $580^{\circ} \mathrm{C}$, achieved extremely high hardness $(820 \mathrm{HV})$ when HIPed at $580^{\circ} \mathrm{C}$ and a pressure of $175 \mathrm{MPa}$. Its ductility was greatly improved when HIPed at temperatures between $700^{\circ} \mathrm{C}$ and $850^{\circ} \mathrm{C}$, while preserving its relatively high strength. The behavior of these nanoscale powders can be understood by considering the three most important processes taking place during the consolidation of any powder: densification, particle bonding, and grain growth. Optimization of these processes may result in unique mechanical properties of the ball milled powders. It was found that these three processes are strongly influenced by the grain size and particle size of the powders investigated, and oxidation level.

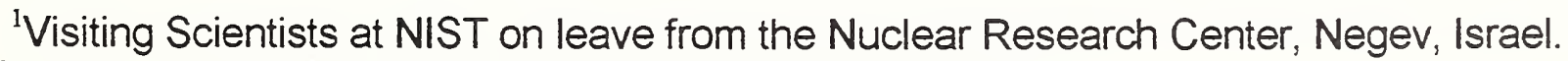

${ }^{2}$ Dept. of Energy (formerly Bureau of Mines), Albany OR.
} 


\section{1) Introduction}

Interest in nanoscale materials has increased in recent years with the realization that unique properties may be obtained from otherwise ordinary materials ${ }^{(1-3)}$. This idea arose from an extrapolation of known grain size effects to nano-grain sizes where such effects are not known to be valid ${ }^{(4,5)}$. The availability of nanoscale materials in reasonable quantities to manufacture bulky bodies would make the experimental evaluation of such predictions possible.

Another reason for interest in nanoscale powders often stated in the literature on these materials ${ }^{(4)}$ is that they may consolidate more readily or more completely than conventional powders. The high specific surface area provides a significant driving force for densification. The extremely fine grain size provides an additional mechanistic route (diffusive flow by Nabarro-Herring or Coble creep) for densification that is available to coarser powders only at extremely high temperatures. Under such conditions, coarsening and pore trapping become severe problems. Coarsening is still an issue even at the more moderate temperatures required to densify nanoscale materials. If the object is to produce dense, nanocrystalline materials, sintering or HIPing temperatures and times must be chosen so as to maximize density and interparticle bonding, and minimize coarsening.

The present research was undertaken to optimize the sintering and HIPing of nanoscale powders to obtain bulk nanocrystalline materials for mechanical properties evaluation, and to find out the impact of particle and grain size effects on the mechanical properties.

\section{2) Experimental Procedures}

The consolidation behavior of two types of nanoscale iron powders was studied. One powder consisted of nanoscale grains in nanoscale particles produced by vapor condensation (NN, for nano-nano). The other powder consisted of nanoscale grains in micrometer scale particles produced by ball milling (NM, for nano-micro). For comparison the consolidation of two microscale grain/microscale particles ( $\mathrm{MM}$, for micro-micro) produced by atomization (MMa) and grinding (MMb) was also characterized. Consolidation was accomplished by a combination of standard techniques including cold closed die pressing, cold isostatic pressing (CIPing), and, after CIPing, sintering or hot isostatic pressing (HIPing). First, the powder was insert in a cylindrical rubber CIPing bags than $\mathrm{ClPed}$ to $350 \mathrm{MPa}$. The entire cycle took about 5 minutes with about 15-30 
seconds at maximum pressure. Usually, the powder was initially loose in the bag, but, in the case of the NN powder, tamping by hand to about $20 \%$ relative density was necessary to achieve a reasonably sized final compact.

Cold closed die pressing was carried out in a special apparatus developed at NIST ${ }^{(6)}$. In essence, it consisted of a carbide cylinder in a steel cylindrical sleeve and two carbide push rods. The compressive force was applied to the push rods by a standard, screw-driven, mechanical testing machine. The actual force applied to the powder was determined using a double load cell system that measured and subtracted any load shedding to the cylinder. In each case a known amount of loose powder was introduced into the cylinder with the lower rod in place. The upper rod was inserted and the pressure applied. The change in the volume of powder was determined from the measured displacement of the push rod.

Sintering of previously CIPed samples was carried out in a vacuum furnace. The vacuum ranged between $0.5 \mathrm{~Pa}$ and $1.0 \mathrm{~Pa}$. Heating to the desired sintering temperature usually took about half hour and control was $\pm 5^{\circ} \mathrm{C}$. In some cases, heating in flowing hydrogen was used to reduce the oxide layer on the iron particles of previously CIPed samples. The procedure employed for deoxidization consisted of first evacuating the chamber to a pressure of $0.5 \mathrm{~Pa}$ to $1.0 \mathrm{~Pa}$ range at room temperature for 20 hours. The chamber was then back filled with a flowing argon $/ 5 \%$ hydrogen mixture at a pressure of one atmosphere. The temperature would then be raised to $375^{\circ} \mathrm{C}$ for 24 hours.

Hot isostatic pressing (HIPing) of the CIPed compacts was performed in a commercial HIP unit. The compacts were first canned in copper tubes which were then evacuated to $10 \mathrm{~Pa}$ and sealed by electron beam welding. They were then placed in the HIP unit and heated to the desired temperature for three hours in pressurized argon gas. The pressure used for HIPing was in every case $175 \mathrm{MPa}$. After HIPing, the copper cans were removed by machining.

After consolidation, the compacts were characterized by optical and scanning electron microscopy, and density measurements.

The apparent tap density measurements were obtained by weighing known volumes of tapped powder. The densities of porous compacts were determined by weighing machined cylinders of known volume. In cases where the bodies were no longer porous to water, the volume was determined by measuring the volume of water displaced by the body.

Mechanical properties characterization involved hardness measurements and compression tests. Vickers hardness tests were done on polished 
metallographic samples using a load of 300 grams for about $12 \mathrm{~s}$. The compression tests were run on a screw-driven mechanical test machine at a cross head speed of $0.02 \mathrm{~mm} / \mathrm{s}$. For these tests, cylindrical samples, $5 \mathrm{~mm}$ in diameter and $9 \mathrm{~mm}$ long, were compressed between carbide platens. Load and displacement data, collected during the test, were later converted to stress and strain.

\section{3) Results}

\section{1) Powder Characterization:}

The starting powders were nominally pure iron which contained varying amounts of oxygen. While oxygen may be thought of as an impurity, it is often intentionally added to deactivate the surface and reduce flammability or explosion hazards associated with fine powders. The oxygen contents of the NN, NM and MM powders are listed in Table 1. Both MM powders contained negligible amounts of oxygen. The morphology of the as-processed powders are presented in Figures $1 \mathrm{a}$ to $1 \mathrm{~d}$. As seen in the figures, the powder particles and grain size ranged from nanoscale grains in nanoscale particles (NN powder) to tens of micrometers grains in tens of micrometers particles (MM powder). The actual sizes are also listed in Table 1, together with their designation. The different powders could readily be distinguished by their apparent relative density which ranged from less than 10\% (similar to snow) for the NN powder to $43 \%$ for the MM powders(Table 1). The finer the particles size of the powder, the lower its apparent density.

\section{2) Consolidation Behavior:}

All powders were cold isostatically pressed (CIPed) to $350 \mathrm{MPa}$ in rubber bags. The resulting densities of consolidated bodies of the different powders are shown in Figures $2 a$, to $2 c$, respectively. After cold consolidation, the NN, MM(a), and $\mathrm{MM}(\mathrm{b})$ compacts were found to hold together fairly well. The NM powder did not CIP well: compacts were friable and returned to powder by rubbing between the fingers. To ascertain whether higher pressures were needed to raise the green strength of NM consolidated bodies, it was cold pressed in a closed die ${ }^{(6)}$ to $2.5 \mathrm{GPa}$. For comparison, MM(a) was also pressed in the same system. The density versus pressure curves are shown in Figure 3 . The density of the MM(a) powder increase with increasing pressure Increasing pressure up to $1.5 \mathrm{GPa}$, where it level of at a value of $95 \%$ the theoretical density. Further pressure 
increasing to $2.5 \mathrm{GPa}$ bring the density to almost the theoretical density while obtained nice solid body. In contrast, the curve for the NM powder did not level off even at the maximum pressure used of $2.5 \mathrm{GPa}$ and the density reached only around $75 \%$ of the theoretical density value. Even after application of this high pressure, the resulting pellet was still friable and could be returned to a powder by rubbing.

The densification due to CIP followed by sintering is compared to HIPing in Figure 2. Sintering for three hours at different temperatures resulted in some density increases. The nanoscale powders' densities depend strongly on sintering temperature until the highest density is reached. For example, NN reached its highest density after sintering at $850^{\circ} \mathrm{C}$ for three hours. As expected, HIPing results in higher densities at lower temperatures than sintering. For example, HIPing NM powders at $580^{\circ} \mathrm{C}$ and $175 \mathrm{MPa}$ for 3 hours reached its highest density whereas, by sintering for 3 hours, it had not reached the same density even at a temperature of $965^{\circ} \mathrm{C}$. The resulting density from some of the treatments is summarizes in Table $2 a$ to $2 d$.

\section{3) Microstructure:}

The microstructures of consolidated NN powder (CIPed and sintered to different temperatures) are shown in Figures $4 a$ through 4d. Microhardness indentations are also seen in these photomicrographs. Sintering above $500^{\circ} \mathrm{C}$ caused oxide particles precipitation. The amount and size of the precipitates increased with increasing sintering temperature. AT $965^{\circ} \mathrm{C}$, an interconnected dual microstructure of iron (light phase) and oxide (dark phase) was observed. As we shall see later, oxide precipitation was observed also in NM powders after sintering at temperatures above $700^{\circ} \mathrm{C}$ but in lower densities levels than the NN powder.

\section{4) Mechanical Properties:}

The hardnesses of NN, NM, and MM(a) consolidated by HIPing or CIPing and then sintering to different temperatures are given in figures $5 a, 5 b$, and $5 c$, respectively. Clearly, the hardness of NN increased dramatically on low sintering temperature $\left(500^{\circ} \mathrm{C}\right)$. In contrast, the NM powder was so weak that reliable hardness data could only be obtained on material sintered at or above $700{ }^{\circ} \mathrm{C}$. Under these sintering conditions, NM was only slightly harder than the as-CIPed powder. HIPing, however, greatly improved NM's hardness, making it much harder than NN. 
The compression stress-strain curves for NN, NM, and MM(a) as a function of the process variables are presented in figures $6 a, b$, and $c$, respectively. MM powder compacts shows extensive ductility for all the sintering temperatures. In contrast, at low sintering temperatures $\left(580^{\circ} \mathrm{C}\right)$, the hydrogen reduced $\mathrm{NN}$ bodies had high strength (1125 MPa), but low ductility. As the sintering temperature increases to $850^{\circ} \mathrm{C}$, the ductility of NN improved to $17 \%$ with a loss in strength to $840 \mathrm{MPa}$. Oxide reduction treatments carried out on $\mathrm{NN}$ effected a decrease in the yield strength, the ultimate compressive strength, and increase the amount of plastic deformation before compressive failure at any given processing temperature. The general mechanical properties behavior with processing temperature was similar to untreated NN except that the peaks in the mechanical properties occurred at lower temperatures.

The sintered NM bodies were, for most sintering conditions, weaker than conventional powder compacts with no ductility at all. At fairly high sintering temperatures $\left(>900^{\circ} \mathrm{C}\right)$ it behaves was similarly to conventional powder compacts. In contrast, HIPing of NM compacts improved the mechanical properties as illustrated in Figure 7 and in Table $2 \mathrm{~b}$.

Examples of ductile, partially brittle, and completely brittle fracture of the cylindrical compression test samples are given in Figure 8 . Brittle bodies brake into many pieces (Figure $8 \mathrm{c}$ ), while partially brittle fracture brake into two pieces. In contrast, ductile bodies did not brake. The diameter of the ductile sample increased while the length decrease. Fractography of the test samples supported the above observations.

In Figure 9, the fracture surface for NM sintered at $700^{\circ} \mathrm{C}$ may be compared with those HIPed at $580^{\circ} \mathrm{C}, 700^{\circ} \mathrm{C}$, and $850^{\circ} \mathrm{C}$. The original particles are still visible in the sintered body and little evidence of bonding can be seen.

The HIPed samples show evidence of complete bonding and the fracture surface consisted of transgranular shear rupture (dimples) fracture at HIPing temperatures of $700^{\circ} \mathrm{C}$ and above. There are particles inside the dimples which were identified by microprobe analysis as oxygen rich particles. Therefore, they may be oxides. The oxides size increased in with increasing consolidation temperature, which in turn caused an increase in the dimples size with increasing temperature.

In figure 10, fractographs of NN sintered to different temperatures $(a, b$, and c) and HIPed at $500{ }^{\circ} \mathrm{C}$ (d) are presented. As can be seen from the figures, the fracture surfaces of the sintered NN bodies at $700^{\circ} \mathrm{C}$ and the HIPed NM 
materials at $700{ }^{\circ} \mathrm{C}$ have similar morphologies, i.e. dimples structure. This fact suggests that sintering NN powders is sufficient to promote bonding.

The fracture morphology of sintered $\mathrm{MM}(\mathrm{a})$ is presented in figure 11 . The original powder particles could be seen on fracture surfaces of material sintered at $580^{\circ} \mathrm{C}$. No original powder particles could be observed when sintered at $700^{\circ} \mathrm{C}$. This suggest that densification and bonding of the MM powders occur at sintering temperatures below $700^{\circ} \mathrm{C}$.

\section{4) Discussion \\ 4.1) General}

The present research evaluates the ability of different consolidation routes to produce fully dense and well bonded nanoscale iron bodies from two types of nanoscale powder (nano-grains in nano-particles-NN, and nano-grains in micro-particles-NM). While densification mechanisms relying on diffusion may be greatly accelerated at relatively low temperatures by small particles and fine grain size, it is necessary to achieve some initial compaction with finely dispersed porosity and an intimate contact between most of the powder particles before these mechanisms become effective. This is usually accomplished by pressing the fine powder to cause particle rearrangement and plastic compaction. It is at this stage that ball milled powders (NM powder) present consolidation difficulties. The NM particles are approximately the same size as the MM(a) powder, but with nanograins the particles are extremely hard, presenting much greater resistance to plastic deformation. Only HIPing allows densification of NM powder to proceed because the material becomes much softer with increasing temperature and grain growth. In contrast, for nano-grains in nano-particles (NN powder) the grain size is larger than the NM grain size (see table 1) and is thus softer than the NM powder. The finer particle size also reduces the pore size. As a consequence, particle rearrangement caused by CIPing is sufficient to make densification by curvature-driven bulk diffusion effective for eliminating the resulting fine porosity during sintering. If heat and pressure are applied (i.e., HIP), a further modest densification occurs compared to CIPing and sintering. In addition, CIPing followed by sintering of NN powders at $500^{\circ} \mathrm{C}$ for $3 \mathrm{hr}$ caused an increase of the hardness from $135 \mathrm{H}_{v}$ of the as CIPed to $439 \mathrm{H}_{v}$, while HIPing for the same time and temperature raised the hardness to $515 \mathrm{H}_{\mathrm{v}}$. In contrast CIPing followed by sintering of NM powders at $580^{\circ} \mathrm{C}$ for $3 \mathrm{hr}$ did not change the hardness of the CIPed body (around $110 \mathrm{H}_{\mathrm{v}}$ ) while HIPing increased the hardness to $820 \mathrm{H}_{\mathrm{v}}$. 
It is possible to achieve densification without good bonding between particles especially at low temperatures. While cold welding has been demonstrated in some systems ${ }^{(7)}$, good bonding between particles of most materials occurs at elevated temperatures where diffusion is significant. However, the rate of grain growth also depends on diffusion and hence, on temperature. Therefore, the achievement of a fully dense material with nanoscale grain size and associated properties requires careful consideration of how densification, bonding, and coarsening respond to the consolidation conditions in each particular powder.

\section{2) The relationship between density, hardness, strength, and ductility}

The main tests used here to study the combined effects of densification, bonding, and coarsening are hardness and uniaxial compression. The hardness of the consolidated body takes into consideration not only the hardness of the material but also the porosity level of the materials $(5,8,9,10)$. Therefore, for example, inspite of the fact that the hardness of the individual particles in the ball-milled powder (NM) exceeds $1000 \mathrm{HV}_{\mathrm{V}}{ }^{(8,11)}$ the hardness of the CIPed powders that are sintered below $850^{\circ} \mathrm{C}$ is very low (around $110 \mathrm{HV}$ ) due to the porosity content and lack of bonding. In contrast, HIPing at temperatures above $500^{\circ} \mathrm{C}$ increases markedly the hardness as well as the density. For example, the hardness of a body HIPed at $370^{\circ} \mathrm{C}$ is $240 \mathrm{H}_{V}$ while the hardness increased to $840 \mathrm{HV}$ when HIPed at $500^{\circ} \mathrm{C}$. At the same time the density increased from $5.9 \mathrm{~g} / \mathrm{ml}$ to $7.1 \mathrm{~g} / \mathrm{ml}$, compared to the theoretical density (including the oxides) of $7.6 \mathrm{~g} / \mathrm{ml}$. This indicate that a major portion of the pores has been eliminated. In the case of Cold Dynamic Compaction (CDC) the densities of those powders ${ }^{(11)}$ reached about 7.3 to $7.4 \mathrm{~g} / \mathrm{ml}$, while retaining the grain size similar to the as processed powder and keeping the work hardening of the ball milled powder. This, in turn caused the hardness to increase $1300 \mathrm{H}_{v}$.

High density and hardness does not imply necessarily the existing of bonding between the particles. For instance, the compression test of a specimen HIPed at $500{ }^{\circ} \mathrm{C}$ resulted in a fracture without any plastic strain at all. This means that due to the consolidation techniques (HIP at low temperatures) the hard particles came into intimate contact (high density) but only with partial bonding. Essentially, the hardness test gives some measure of the plastic flow properties, but it correlates with the density more than with the 
degree of bonding. The uniaxial compression test measures the compressive strength in the case of a brittle material. For more ductile materials, it measures the plastic yield strength and work-hardening behavior, and gives some indication about the ductility. This ductility level provides insight into how well the particles have bonded together.

\section{3) The role of oxygen in powder consolidation.}

It is important to remember that the nanograin materials studied here always contain a significant amount of oxygen present as iron oxide. Full density for the nanoscale materials is therefore somewhat less than that for pure iron (7.6 $\mathrm{gm} / \mathrm{ml}$ ) because iron oxide is less dense than iron. This hard, oxide phase strengthens the resulting composite considerably, affects the consolidation behavior, and complicates comparisons between the nanograin material and more conventional iron compacts. It is possible to make nanograin iron powder without oxygen and some researchers ${ }^{(8)}$ are doing it. However, the handling problems associated with oxygen-free iron are considerable and it is likely that the passivated material studied here is of greater commercial interest. The densification of hydrogen reduced nanoscale materials are shown on figure 2. Although reduced NN compacts are denser than the unreduced ones, metallography reveals some small amount of oxide remaining in the hydrogen reduced materials. The increase in density was accompanied with hardness decrease associated with the reduction in oxide content.

The amount of oxygen in the different powders might influence the consolidation behavior in three ways: (i) very fine precipitates of oxide might have a greatly increase the particles' strength; (ii) bonding might be hindered by the presence of oxides on the particle surfaces; and (iii) oxide might limit or reduce grain growth. The effect of oxygen on grain growth and strengthening is now under investigation.

\section{4) Hall-Petch relationship}

The fully dense samples produced in this study have grain sizes of 100 nanometers and up. It is appropriate to use these as a test of whether the Hall-Petch relation can be extrapolated to such fine grain sizes ${ }^{(12,13)}$. Figure 12 shows the dependence of hardness on the inverse root of grain diameter for all materials which had reached full density. Figure 13 shows the dependence of yield strength on the same parameter. It should be noted that some of the highest compression strength samples broke before they clearly yielded. While 
significant hardening and strengthening results from reducing the grain size, the magnitude of the effect is not as great as would be expected from a linear extrapolation of the large grain size material results into the nanoscale region, inspite of the additional strengthening from the oxide. This result agrees with the idea of Nieh and Wadsworth ${ }^{(11)}$ that the Hall-Petch effect is overtaken at small grain sizes by other mechanisms that lead to lower the strength with decreasing grain size. Whether this phenomena, which was observed by many others ${ }^{(8,10,13)}$, is intrinsic to fine grain sizes or the result of incomplete consolidation in their materials is not always clear in the literature. The results presented here in Figures 12 and 13 are taken from samples for which the hardness has peaked and the density has reached a plateau. These samples are believed to have reached full density. The nanograined materials, though extremely strong, are not as hard as would be predicted by a Hall-Petch fit to the properties of large grained material. It would be necessary to explore even finer grain sizes than those studied here to observe whether a softening with decreasing grain size actually occurs.

\section{Conclusions}

The uniqueness of bulk nanocrystalline materials is the small grain size. During the process of consolidation of these materials, the most important thing to preserve, at least partially, is the grain size. Ball-milled powder has an extremely small starting grain size. The size and hardness of the particles in ball-milled powder is such that processes like HIPing must be used to consolidate it effectively. Vapor condensed powder has extremely small particles that are not so hard and consolidation proceeds easily by sintering at relatively low temperatures. However, the resulting, fully dense body has lower hardness than, ball-milled material HIPed to full density. The hardness and the strength of both nanograined powders compacted bodies is substantially higher than these of regular powders. It seems that the oxides formed during consolidation might be an important governing the strength and microstructure of the compacted bodies.

The behavior of these nanoscale powders can be understood by considering the three most important processes taking place during the consolidation of any powder: densification, particle bonding, and grain growth. Optimization of these processes may result in unique mechanical properties of the ball milled powders. It was found that these three processes are strongly influenced by the grain size and particle size of the powders investigated, and oxidation level. 


\section{Acknowledgments}

The authors would like to thank Dr. R. Shull for many valuable discussions throughout the performance of this research. In addition, the assistance of Dr. J. Ritter in hydrogen reduction, Dr. A. Shapiro in scanning electron microscopy, Dr. R.J. Schaefer and R. Jiggetts in HIPing, Dr. J. Blendell in CIPing, and Dr. R. Clough in mechanical testing is gratefully acknowledged.

\section{References}

(1) H. Gleiter, "Nanocrystalline Materials," Progress in Materials Science 33 223-315 (1989).

2) Research Opportunities for Materials with Ultrafine Microstructures, National Materials Advisory Board Report No. 454 (1989).

3) R. D. Shull, First NIST Workshop on Nanostructured Material, National Institute of Standards and Technology Report No. NISTIR 5456 (1994).

(4) C. Suryanarayana, "Nanocrystalline Materials," International Materials Reviews $\underline{40}$ pp. 41-64, (1995).

(5) V. G. Gryaznov, M. Yu. Gutkin, A. E. Romanov, and L.I. Trusov, "On the Yield Stress of Nanocrystals," J. of Materials Science 28 4359-4365 (1993).

(6) W. Chen, A. Pechenik, S. J. Dapkunas, G. J. Piermarini, and S. Malghan, "Novel Equipment for the Study of the Compaction of Fine Powders," J. American Ceramic Society 77 1005-1010 (1994).

(7) M. P. Dariel, D. S. Lashmore, and M. Ratzker, "New Technology for Mercury Free Metallic Dental Restorative Alloys," Powder Metallurgy 37 p. 88 (1994).

(8) G. E. Fougere, J. R. Weertman, and R. W. Siegel, "Processing and Mechanical Behavior of Nanocrystalline Fe," Nanostructured Materials, 5 127-134 (1995).

(9) J.R. Groza, and R.J. Dowding, "Nanoparticulate materials densification" Nanostructured Materials Vol. 7 (1996) pp. 749-768.

10) J. R. Weertman, M. Niedzielka, and C. Youngdahl, "Hall-Petch Behavior in Nanocrystalline Metals," in Mechanical Properties and Deformation Behavior of Materials Having Ultra-Fine Micro-structures, edited by M. Nastasi, D. M. Parkin, and H. Gleiter, published by Kluwer Academic Publishers, Dordrecht (199?).

11) A. Munitz, Z. Livne, J. C. Rawers and R. J. Fields, "Cold Compaction of Nanograin Iron Alloys", to be published in Conf. Hawaii, 1996

12) T. G. Nieh and J. Wadsworth, "Hall-Petch Relation in Nanocrystalline Solids," Scripta Metallurgica et Materialia 25 955-958 (1991).

13) J. S. C. Jang and C. C. Koch, "The Hall-Petch Relationship in Nanocrystalline Iron Produced by Ball Milling," Scripta Metallurgica et Materialia 24 1599-1604 (1990). 


\section{List of Tables}

Table 1. Characteristics of as-received powders used in the present study.

Table 2. Density and hardness of consolidated a) NN, b) NM, c) MMa, and d) MMb powders resulting from various processing routes. 


\section{List of Figures}

Figure 1. Morphology of the starting powders:(a) NN, (b) NM, (c) MM(a), and (d) MM(b).

Figure 2. Density of compacts after CIPing, sintering, and HIPing starting with (a) MM powder, (b) NM powder, and(c) NN powder.

Figure 3. Density versus pressure in closed die compaction for two types of powder.

Figure 4. Examples of microstructures of consolidated NN powder sintered at (a) $500^{\circ} \mathrm{C}$, (b) $580^{\circ} \mathrm{C}$, (c) $700^{\circ} \mathrm{C}$, and (d) $965^{\circ} \mathrm{C}$.

Figure 5. Hardness of compacts that were first CIPed, then sintered or HIPed at different temperatures.

Figure 6. Selected stress-strain curves from compression tests on (a) NN, (b) NM, and (c) MMa.

Figure 7. Compressive yield stress of NM compacts that were CIPed, sintered, or HIPed.

Figure 8. Fracture behavior of test cylinders: (a) ductile, (b) partially brittle, and (c) brittle.

Figure 9. Fracture surfaces of NM after (a) sintering at $700^{\circ} \mathrm{C}$ or HIPing at (b) $580^{\circ} \mathrm{C}$, (c) $700^{\circ} \mathrm{C}$, or (d) $850^{\circ} \mathrm{C}$

Figure 10. Fracture surfaces of $\mathrm{NN}$ after sintering at (a) $580^{\circ} \mathrm{C}$, (b) $700^{\circ} \mathrm{C}$, (c) $965^{\circ} \mathrm{C}$, or (d) HIPing at $500^{\circ} \mathrm{C}$.

Figure 11. Fracture surfaces of $\mathrm{MM}(\mathrm{a})$ after sintering at (a) $580^{\circ} \mathrm{C}$ and (b) $700^{\circ} \mathrm{C}$.

Figure 12. Hardness of iron as a function of grain size.

Figure 13. Yield strength of iron as a function of grain size. 
Table 1. Characteristics of powders used in the present study.

\begin{tabular}{|l|l|l|l|l|l|}
\hline Code & $\begin{array}{l}\text { Powder } \\
\text { Production } \\
\text { Process }\end{array}$ & $\begin{array}{l}\text { Particle } \\
\text { Diameter } \\
{[\mu \mathrm{m}]}\end{array}$ & $\begin{array}{l}\text { Grain } \\
\text { Size } \\
{[\mathrm{nm}]}\end{array}$ & $\begin{array}{l}\text { O+N } \\
\text { Concentration } \\
{[w t . \%]}\end{array}$ & $\begin{array}{l}\text { Tap } \\
\text { Density } \\
{[\%]}\end{array}$ \\
\hline $\mathrm{NN}$ & Evap/Cond & $.15 \pm .05$ & $55 \pm 25^{*}$ & $5.7 \% \mathrm{O}$ & $7.5 \pm 2.5$ \\
\hline $\mathrm{NM}$ & Ball Mill & $\begin{array}{l}\text { Bimodal } \\
1.5 \pm 0.5 \\
.15 \pm .05\end{array}$ & $\begin{array}{c}6.5 \pm \\
1.5^{*}\end{array}$ & $\begin{array}{l}1.9 \% \mathrm{~N} \\
2 \% \mathrm{O}\end{array}$ & $36 \pm 2.5$ \\
\hline $\mathrm{MM}(\mathrm{a})$ & Atomized & $7 \pm 1$ & $>1000$ & $<<1 \% \mathrm{O}$ & $40 \pm 2.5$ \\
\hline $\mathrm{MM}(\mathrm{b})$ & Grinding & $60 \pm 10$ & $>1000$ & $<<1 \% \mathrm{O}$ & $43 \pm 2.5$ \\
\hline
\end{tabular}

* From $\mathrm{X}$-ray analysis.

Table 2a: Behavior of consolidated NN powder. There is an uncertainty of about $5 \%$ in all the values.

\begin{tabular}{|c|c|c|c|c|c|}
\hline $\begin{array}{l}\text { Fracture Behavior } \\
\text { (strain to Fracture) }\end{array}$ & $\begin{array}{l}\text { compressive } \\
\text { Max. (MPa) }\end{array}$ & $\begin{array}{l}\text { compressive } \\
\text { yield(MPa) }\end{array}$ & $\begin{array}{l}\text { Hardness, } \\
\mathrm{H}_{\mathrm{V}}\left(\mathrm{Kg} / \mathrm{mm}^{2}\right)\end{array}$ & $\begin{array}{l}\text { Density } \\
(\mathrm{g} / \mathrm{ml})\end{array}$ & $\begin{array}{l}\text { Processing } \\
\text { History }{ }^{(a)}\end{array}$ \\
\hline Failed on lathe $(0 \%)$ & - & - & 110 & 4.2 & as CIPed \\
\hline Failed on lathe $(0 \%)$ & - & - & 135 & - & $\mathrm{S}^{(\mathrm{b})} 375 \mathrm{C} / 24 \mathrm{hrs}$ \\
\hline Cleaved & 1400 & 1400 & 410 & 5.9 & $\mathrm{H}_{2}{ }^{(\mathrm{c})}$ \\
\hline Failed on lathe $(0 \%)$ & - & - & 440 & 6.3 & $\mathrm{~S} 500 \mathrm{C} / 3 \mathrm{hrs}$ \\
\hline Cleaved & 1800 & 1800 & 520 & 6.8 & $\mathrm{P}^{(\mathrm{d})} 500 \mathrm{C}$ \\
\hline Cleaved & 1700 & 1700 & 680 & 6.3 & $\mathrm{H}_{2}^{(\mathrm{c})}-\mathrm{P} 500 \mathrm{C}$ \\
\hline Cleaved & --- & ---- & 430 & 6.3 & S580C \\
\hline Shear fracture (2\%) & 1125 & 950 & 250 & 6.3 & $\mathrm{H}_{2}{ }^{(\mathrm{c})} \mathrm{S} 585 \mathrm{C} / 3 \mathrm{hrs}$ \\
\hline $\begin{array}{l}\text { Ductile Fe, Brittle } \\
\text { Oxide }(0.05 \%)\end{array}$ & 1200 & 1160 & 380 & 6.6 & S700C/3hrs \\
\hline Shear fracture $(17 \%)$ & 840 & 730 & 300 & 7.0 & $\mathrm{~S} 850 \mathrm{C} / 3 \mathrm{hrs}$ \\
\hline Shear fracture $(14 \%)$ & 700 & 350 & 230 & 6.9 & $\begin{array}{l}\text { S300C/18hrs- } \\
\text { S965C/3hrs }\end{array}$ \\
\hline Ductile(e) $^{(e)}$ & 1500 & 280 & & 7.5 & $\begin{array}{l}\mathrm{H}_{2}{ }^{(\mathrm{c})} \mathrm{S} 585 \mathrm{C} / 3 \mathrm{hrs} \\
-\mathrm{S} 965 \mathrm{C} / 3 \mathrm{hrs}\end{array}$ \\
\hline
\end{tabular}

(a) all the samples were furst CIPed at $350 \mathrm{MPa}$, then processed as indicated

(b) $\mathrm{S}$ indicates sintered in vacuum of $1 \mathrm{~Pa}$.

(c) $\mathrm{H}_{2}$ indicates sintered in $\mathrm{H}_{2}$ atmosphere at $375^{\circ} \mathrm{C}$ for 24 hours.

(d) P indicates HITPed at pressure of $175 \mathrm{MPa}$ for 3 hours.

(e) Did not fail by fracture, test stopped after excessive deformation. Therefore the value is meaningless and represent the fact that the sample is very ductile. 
Table 2b: Behavior of consolidate NM powder. There is an uncertainty of about $5 \%$ to $10 \%$ in all the values.

\begin{tabular}{|c|c|c|c|c|c|}
\hline $\begin{array}{l}\text { Fracture Behavior } \\
\text { (strain to Fracture) }\end{array}$ & $\begin{array}{l}\text { compressive } \\
\text { Max. (MPa) }\end{array}$ & $\begin{array}{l}\text { compressive } \\
\text { yield }(\mathrm{MPa})\end{array}$ & $\begin{array}{l}\text { Hardness, Hv } \\
\left(\mathrm{kg} / \mathrm{mm}^{2}\right)\end{array}$ & $\begin{array}{l}\text { Density } \\
(\mathrm{g} / \mathrm{mL})\end{array}$ & $\begin{array}{l}\text { Processing } \\
\text { History(a) } \\
\end{array}$ \\
\hline Brittle fracture $(0 \%)$ & -- & -- & 120 & 4.6 & as CIPed \\
\hline Brittle fracture $(0 \%)$ & -- & --- & 120 & 4.6 & $S^{(b)} 370 C$ \\
\hline Brittle fracture $(0 \%)$ & -- & 660 & 240 & 5.9 & $P^{(d)} 370 C$ \\
\hline Brittle fracture $(0 \%)$ & --- & --- & 120 & 4.65 & $\mathrm{~S}^{(\mathrm{b}) 500 \mathrm{C}}$ \\
\hline Brittle fracture $(0 \%)$ & $\ldots$ & 800 & 840 & 7.0 & $P^{(d)} 500 C$ \\
\hline Brittle fracture $(0 \%)$ & -- & $\cdots$ & 120 & 4.7 & $\mathrm{~S}^{(b)} 580 \mathrm{C}$ \\
\hline Brittle fracture $(0 \%)$ & 1200 & 1200 & 820 & 7.1 & $\mathrm{P}^{(\mathrm{d})} 580 \mathrm{C}$ \\
\hline Failed on lathe $(0 \%)$ & $-\cdots$ & -- & -- & -- & $\mathrm{H}_{2}{ }^{(\mathrm{c})}-\mathrm{S}^{(\mathrm{b})} 585 \mathrm{C} / 3 \mathrm{hrs}$ \\
\hline Brittle fracture ( $1 \%)$ & $-\cdots$ & 110 & 120 & 4.94 & S700C/18hrs \\
\hline Brittle fracture $(0 \%)$ & 2100 & 2100 & 570 & 7.1 & P700C \\
\hline Brittle fracture $(0 \%)$ & 1560 & 1380 & 580 & 7.5 & $\mathrm{H} 2-\mathrm{P} 700 \mathrm{C}$ \\
\hline $\begin{array}{l}\text { Ductile fracture } \\
(15 \%)\end{array}$ & 330 & 160 & 140 & 5.38 & $\begin{array}{l}\text { S300C/1hrs- } \\
\text { S850C/3hrs }\end{array}$ \\
\hline $\begin{array}{l}\text { Ductile Fe, Brittle } \\
\text { Oxide }(3 \%)\end{array}$ & 1390 & 1200 & 470 & 7.1 & P850C \\
\hline Ductile(e) & 1700 & 110 & 160 & 7.0 & S965C/120hrs \\
\hline Ductile(e) $^{(\mathrm{e}}$ & 1000 & 610 & 300 & 6.9 & P965C/3hrs \\
\hline
\end{tabular}

(a) all the samples were first CIPed at $350 \mathrm{MPa}$, then processed as indicated

(b) $\mathrm{S}$ indicates sintered in vacuum of $1 \mathrm{~Pa}$.

(c) $\mathrm{H}_{2}$ indicates sintered in $\mathrm{H}_{2}$ atmosphere at $375^{\circ} \mathrm{C}$ for 24 hours.

(d) P indicates HIPed at pressure of $175 \mathrm{MPa}$ for 3 hours.

(e) Did not fail by fracture, test stopped after excessive deformation. Therefore the value is meaningless and represent the fact that the sample is very ductile. 
Table 2c: Behavior of consolidate MM(a) powder. There is an uncertainty of about $5 \%$ to $10 \%$ in all the values.

\begin{tabular}{|l|l|l|l|l|l|}
\hline$(7 \%)$ & --- & --- & 40 & 5.7 & $\mathrm{~S}^{(b)} 25 \mathrm{C} / 18 \mathrm{hrs}$ \\
\hline$(7 \%)$ & 180 & 120 & 40 & 5.7 & $\mathrm{~S}^{(b)} 500 \mathrm{C} / 18 \mathrm{hrs}$ \\
\hline Partial brittle(15\%) & 180 & 120 & 40 & 5.7 & $\mathrm{~S} 580 \mathrm{C} / 18 \mathrm{hrs}$ \\
\hline Ductile (55\%) & 400 & 150 & 54 & 6.1 & $\mathrm{~S} 700 \mathrm{C} / 18 \mathrm{hrs}$ \\
\hline Ductile(e) & 1700 & 530 & 170 & 7.8 & $\mathrm{P}^{(\mathrm{d})} 700 \mathrm{C}$ \\
\hline Ductile(e) & 1500 & 225 & 80 & 7.6 & $\begin{array}{l}\text { S300C/1hrs- } \\
\text { S850C/3hrs }\end{array}$ \\
\hline Ductile(e) $^{(e)}$ & 1250 & 380 & 60 & 7.8 & $\mathrm{P} 850 \mathrm{C}$ \\
\hline Ductile(e) $^{(e)}$ & 1700 & 120 & 60 & 6.8 & S965C/120hrs \\
\hline
\end{tabular}

Table 2d: Behavior of consolidate $\mathrm{MM}(\mathrm{b})$ powder. There is an uncertainty of about $5 \%$ to $10 \%$ in all the values.

\begin{tabular}{|l|l|l|l|l|l|}
\hline Ductile(e) $^{(e)}$ & 1100 & 100 & 50 & 6.8 & $\begin{array}{l}\mathrm{S}^{(\mathrm{b})} 300 \mathrm{C} / 18 \mathrm{hrs}- \\
\text { S965C/4hrs }\end{array}$ \\
\hline Ductile(e) $^{(e)}$ & 1700 & 100 & 40 & 6.5 & S965C/120hrs \\
\hline
\end{tabular}

(a) all the samples were first CIPed at $350 \mathrm{MPa}$, then processed as indicated

(b) $\mathrm{S}$ indicates sintered in vacuum of $1 \mathrm{~Pa}$.

(c) $\mathrm{H}_{2}$ indicates sintered in $\mathrm{H}_{2}$ atmosphere at $375^{\circ} \mathrm{C}$ for 24 hours.

(d) P indicates HIPed at pressure of $175 \mathrm{MPa}$ for 3 hours.

(e) Did not fail by fracture, test stopped after excessive deformation. Therefore the value is meaningless and represent the fact that the sample is very ductile. 


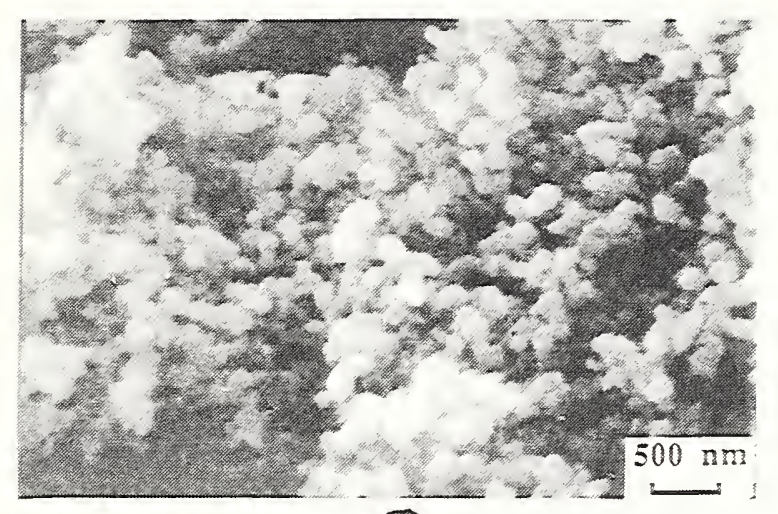

2

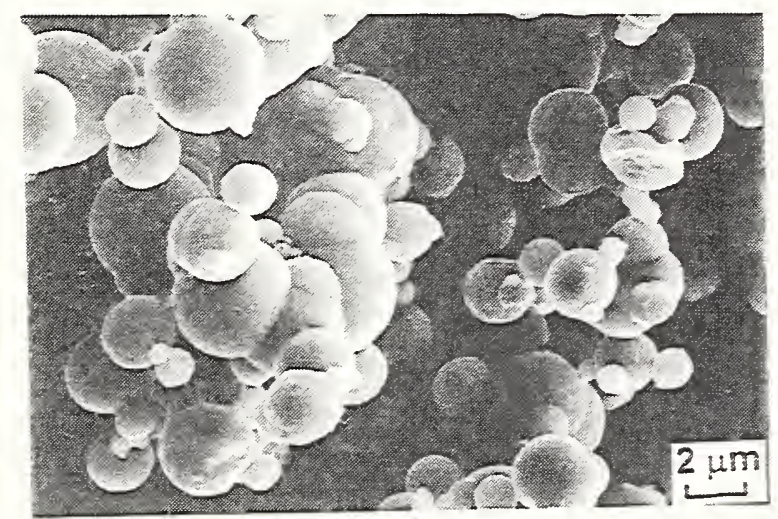

c
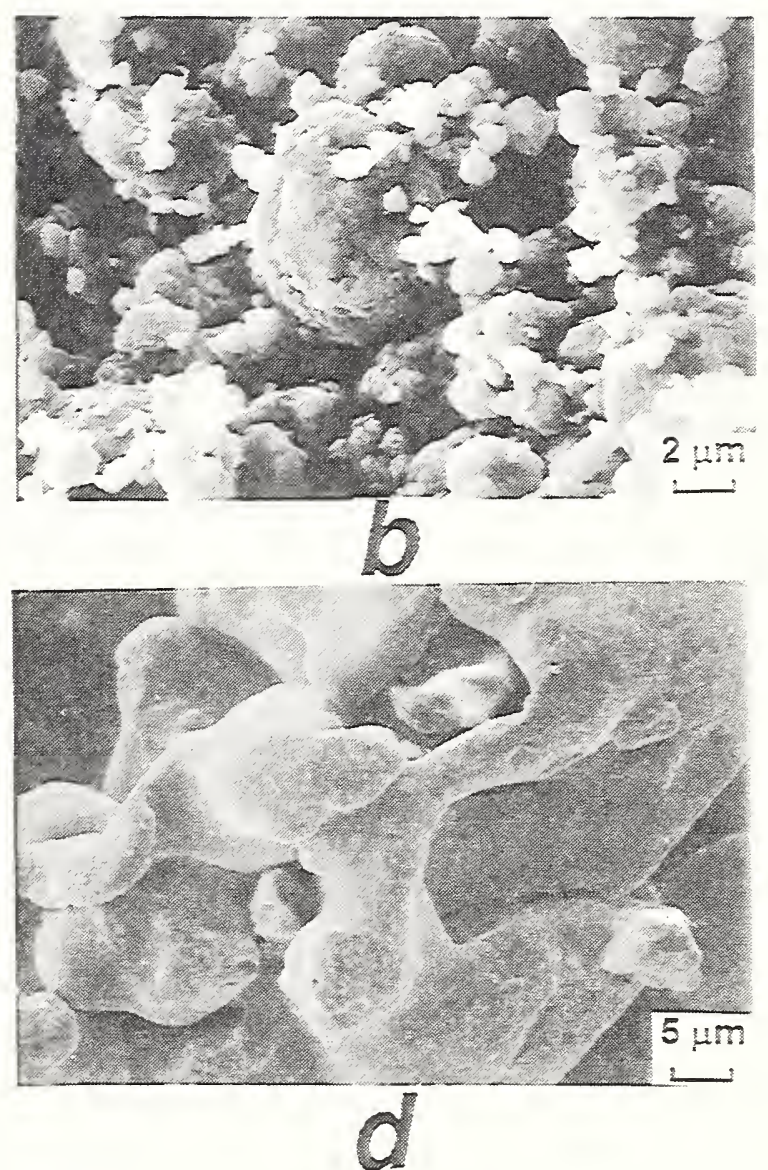

Figure 1. Morphology of the starting powders:(a) NN, (b) NM, (c) MM(a), and (d) MM(b). 

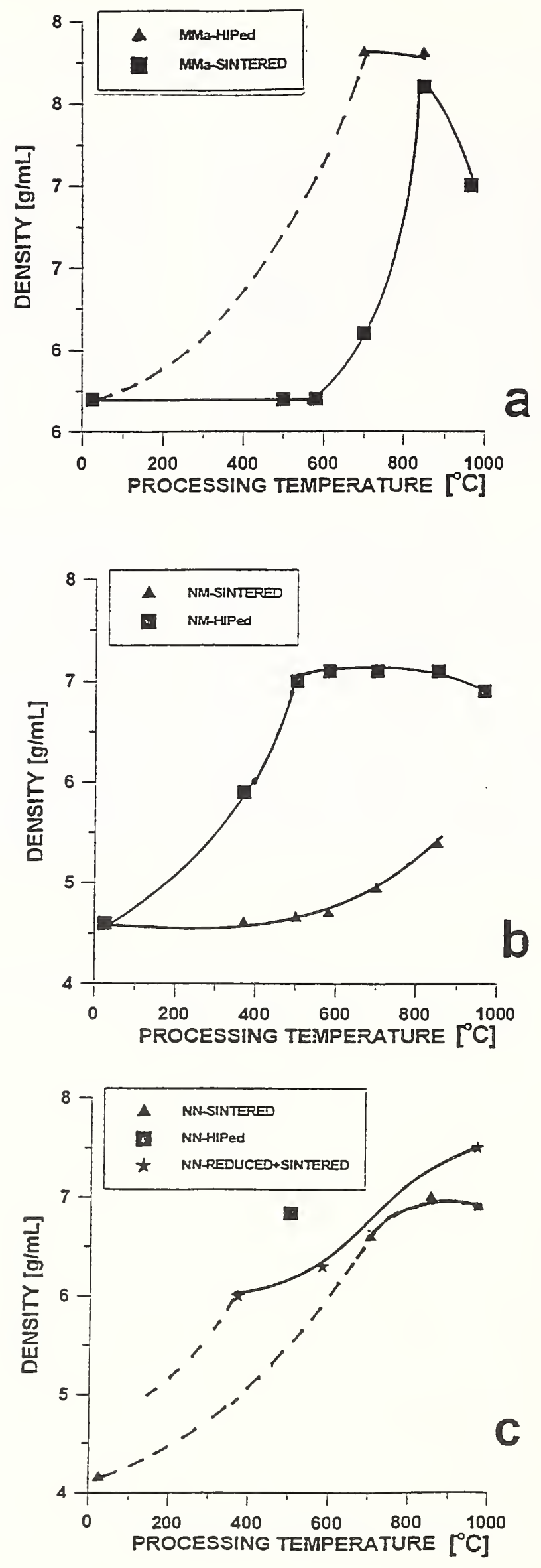

Figure 2. Density of compacts after CIPing, sintering, and HIPing starting with (a) MM powder,(b) NM powder, and(c) NN powder. 


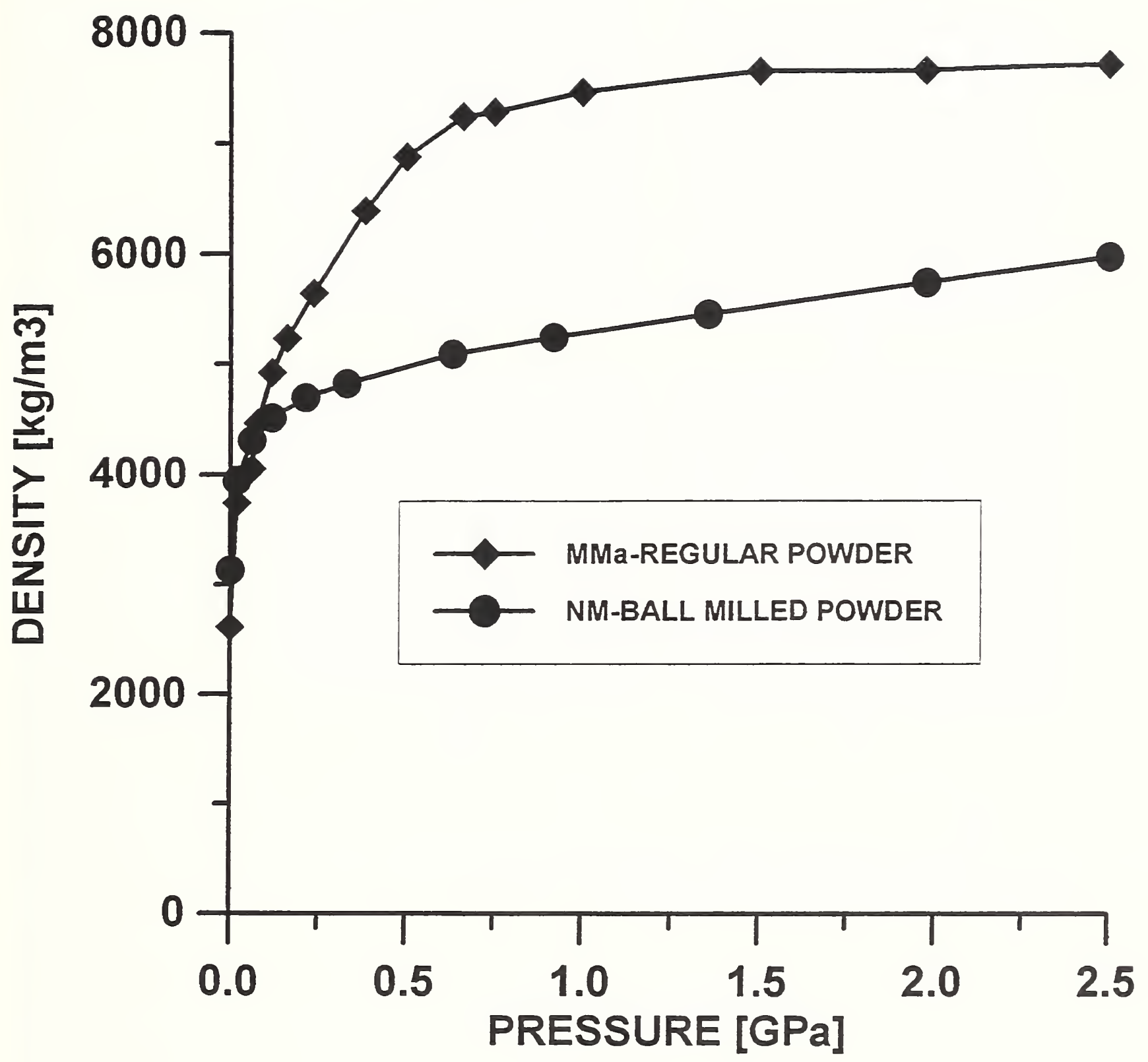

Figure 3. Density versus pressure in closed die compaction for two types of powder. 

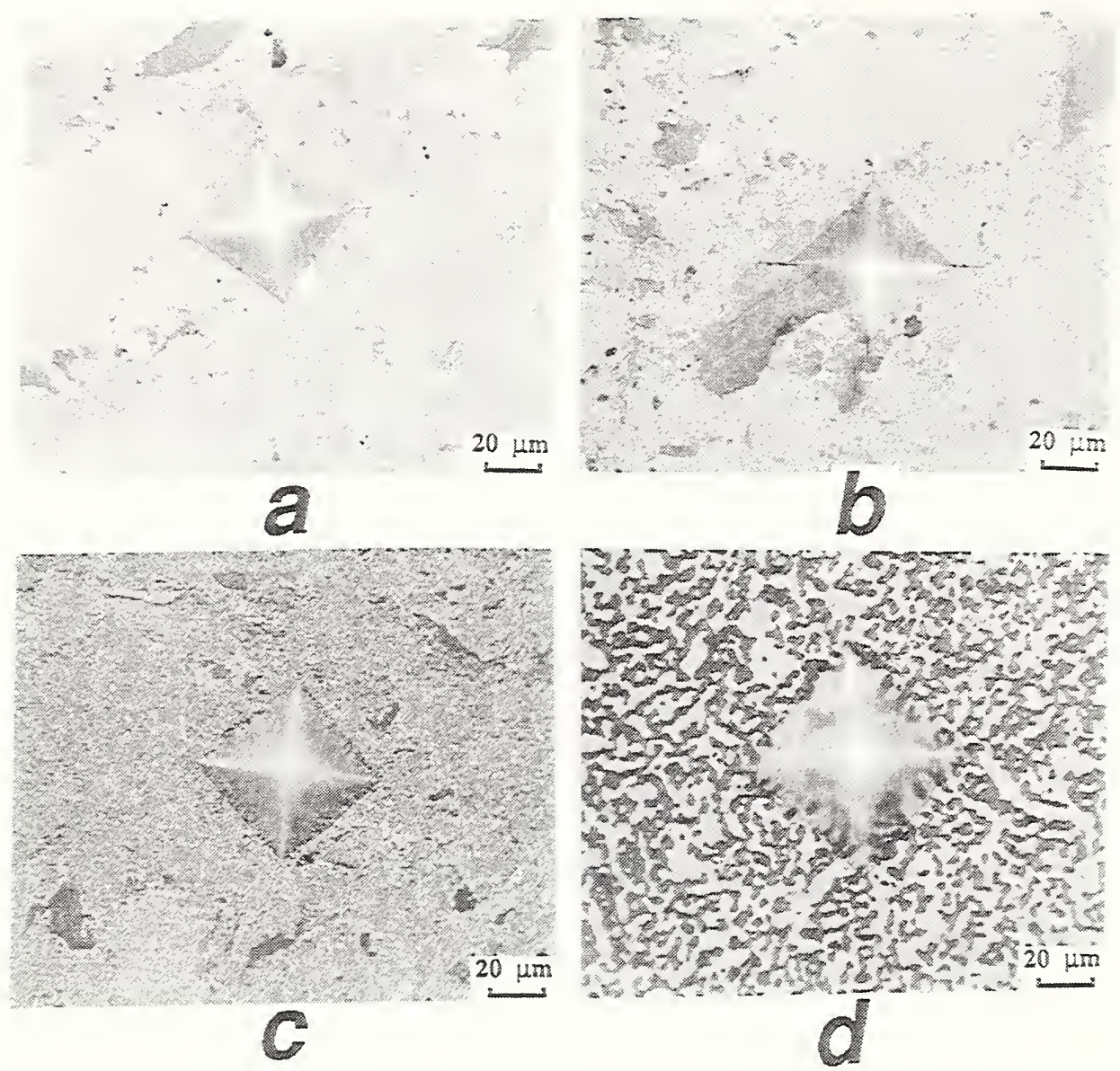

Figure 4. Examples of microstructures of consolidated NN powder sintered at (a) $500^{\circ} \mathrm{C}$, (b) $580^{\circ} \mathrm{C}$, (c) $700^{\circ} \mathrm{C}$, and (d) $965^{\circ} \mathrm{C}$. 

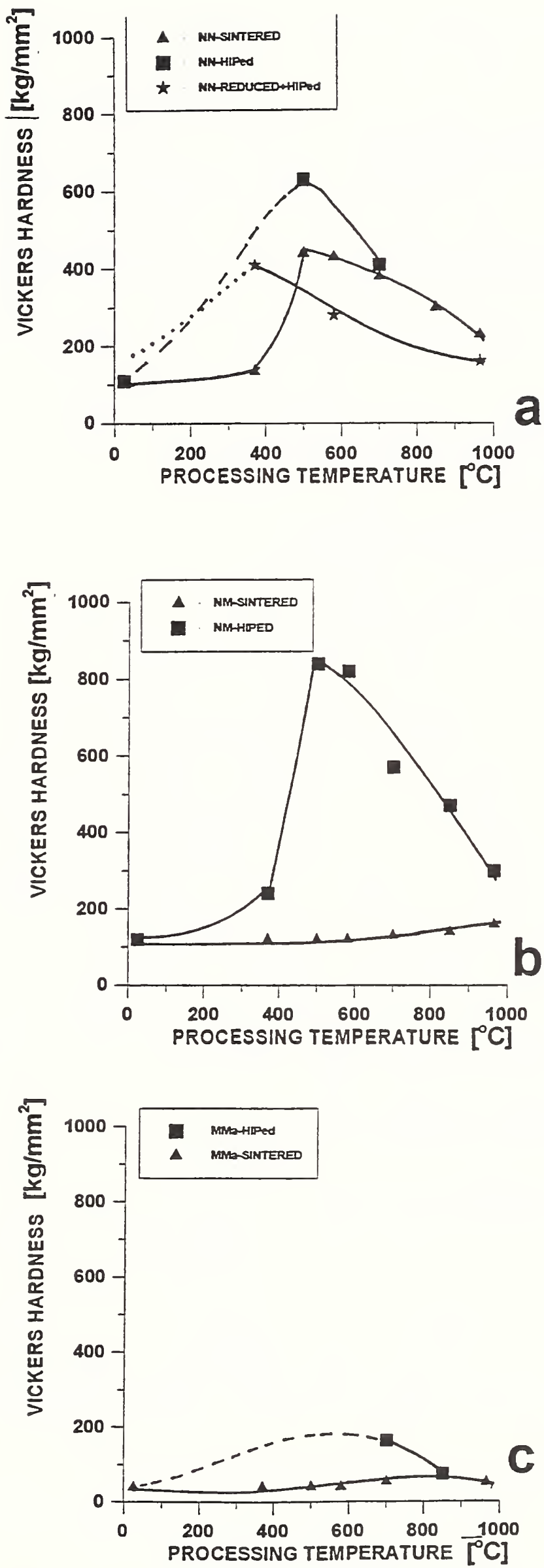

Figure 5. Hardness of compacts that were first CIPed, then sintered or HIPed at different temperatures. 

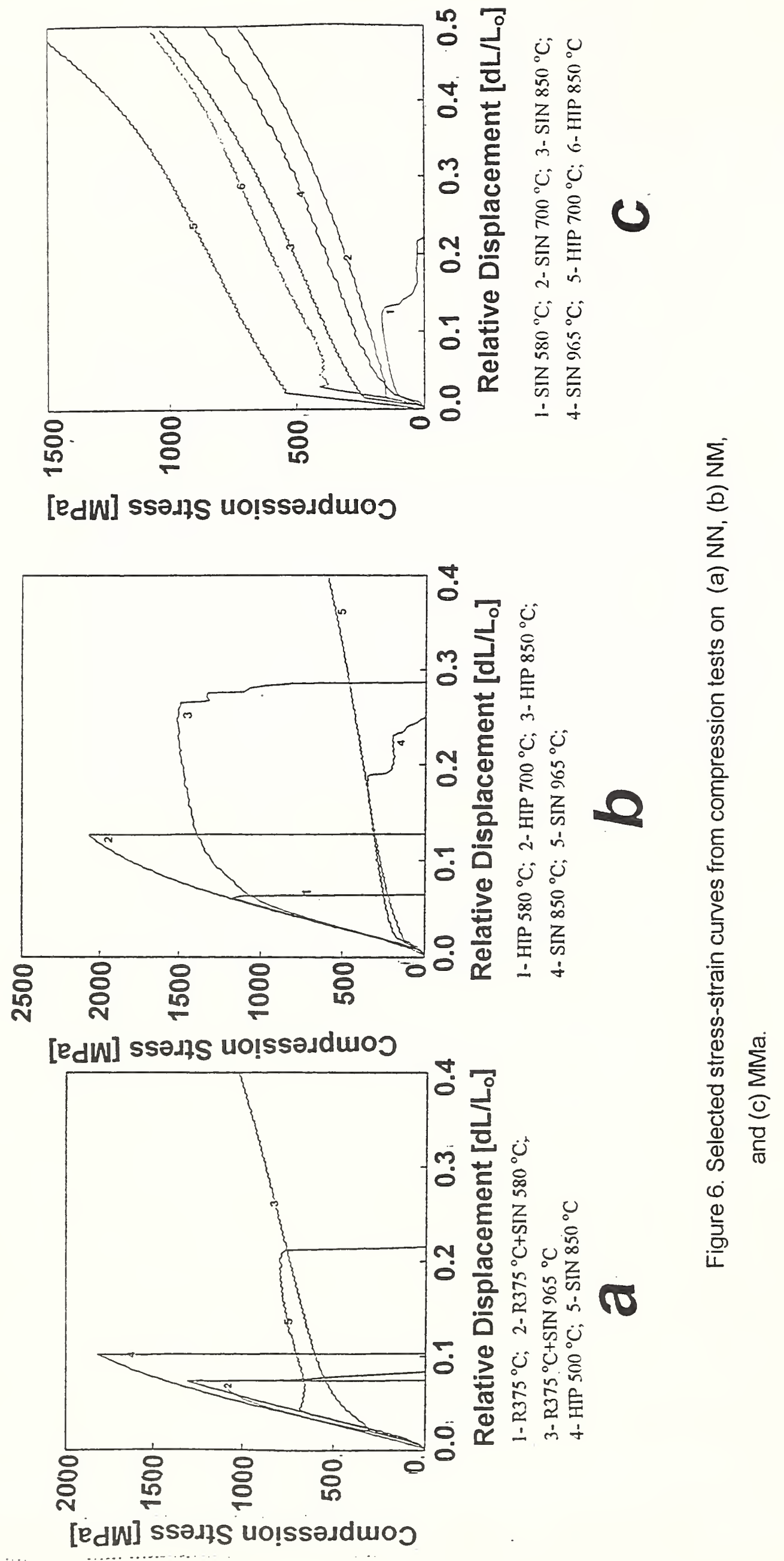
MMa-HIPed

- MMa-SINTERED

$\longrightarrow$ NM-SINTERED

NM-HIPed $\longrightarrow$ NN-SINTERED

$\longrightarrow$ NN-HIPed

$\square$ NN-REDUCED+SINTERED

$\stackrel{\wedge}{\simeq}$ NN-REDUCED+HIPed

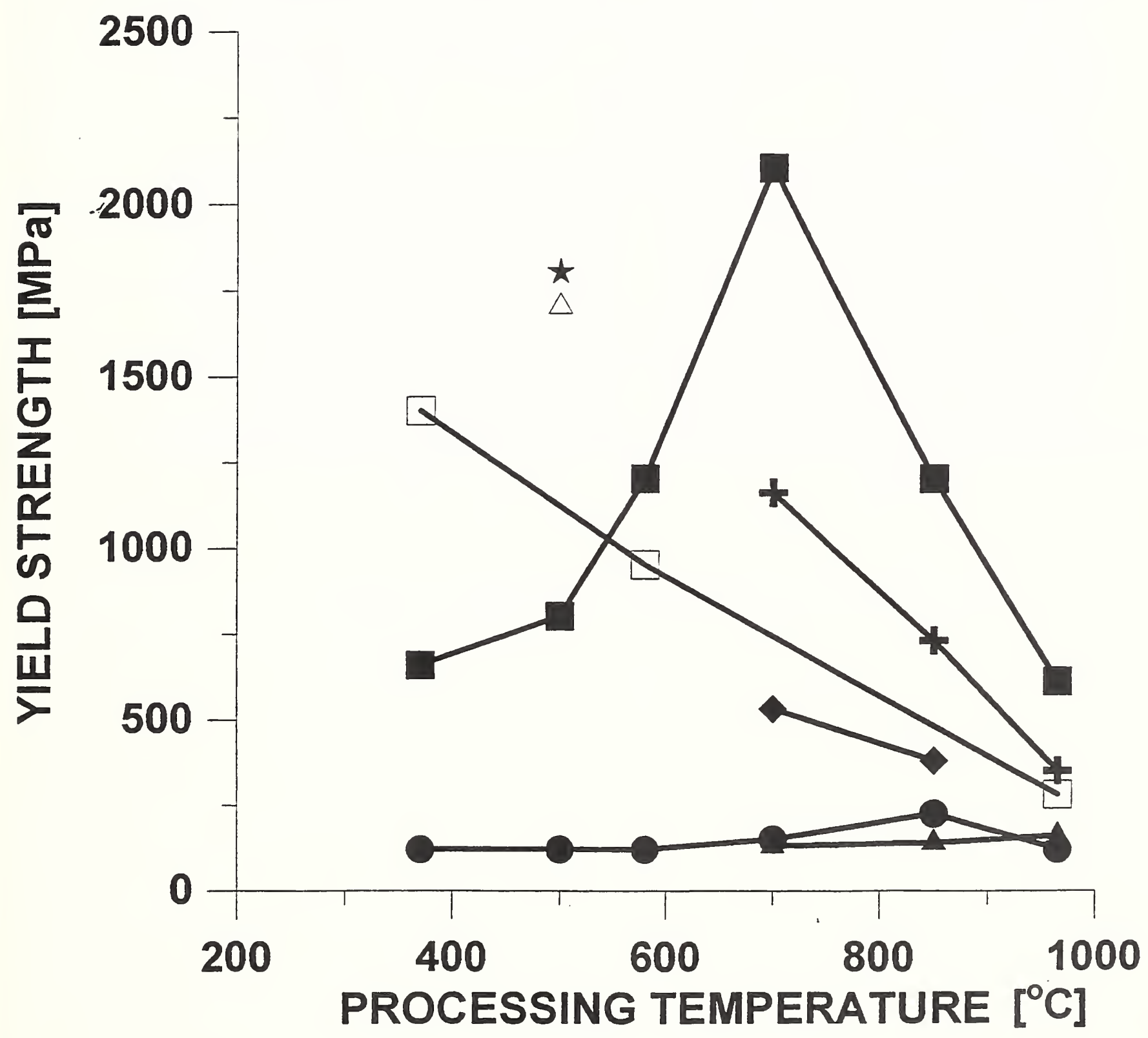

Figure 7. Compressive yield stress of NM compacts that were CIPed, sintered, or HIPed. 

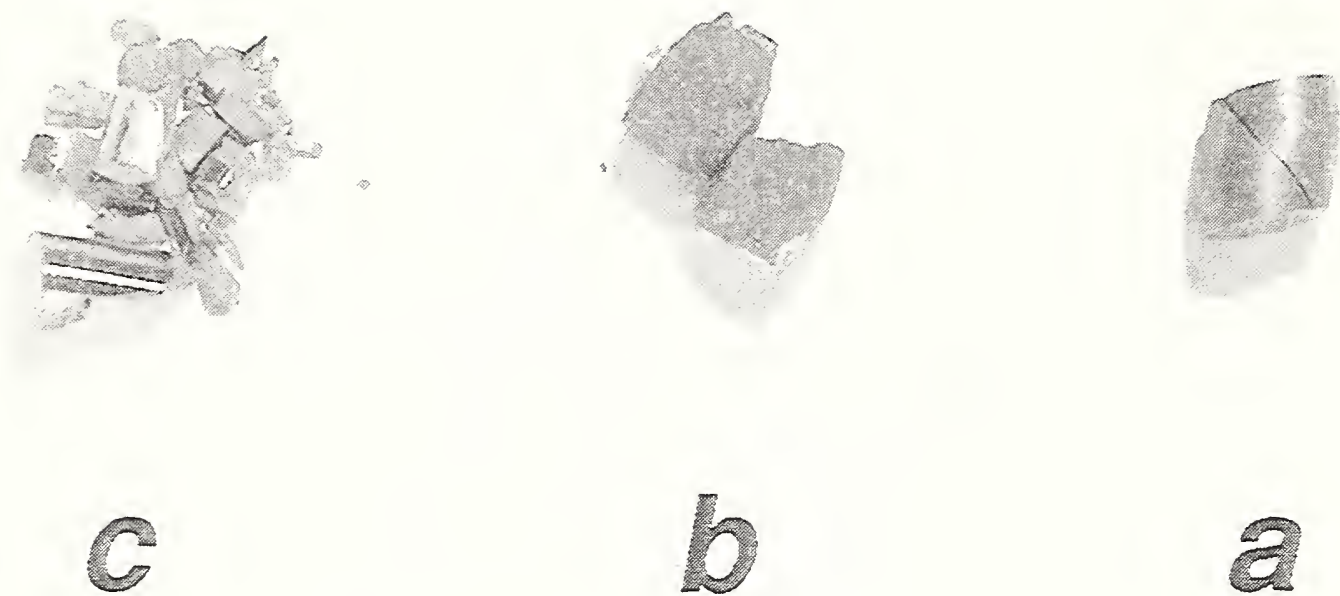

Figure 8. Fracture behavior of test cylinders: (a) ductile, (b) partially brittle, and (c) brittle. 

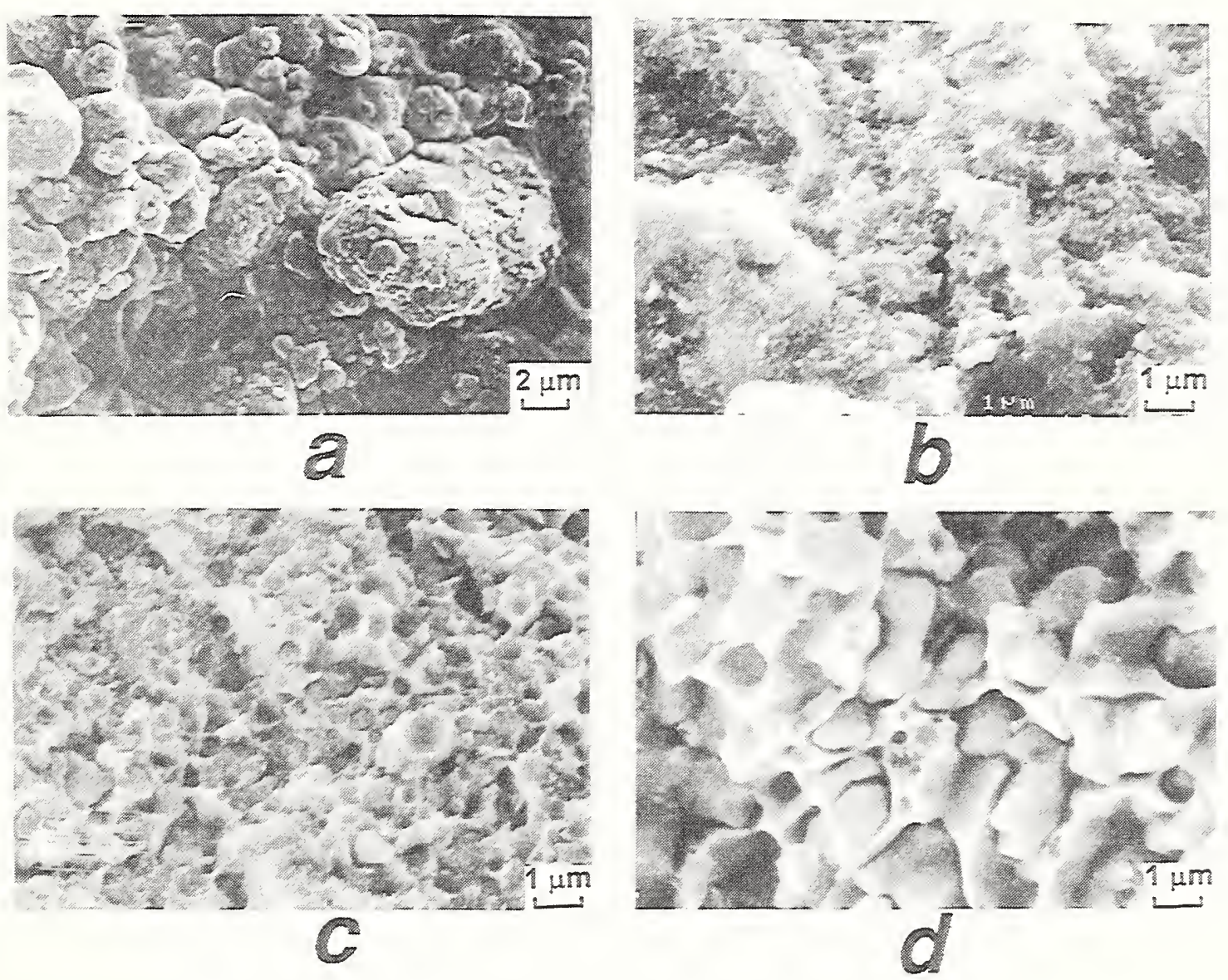

Figure 9. Fracture surfaces of NM after (a) sintering at $700^{\circ} \mathrm{C}$ or HIPing at (b) $580^{\circ} \mathrm{C}$, (c) $700^{\circ} \mathrm{C}$, or (d) $850^{\circ} \mathrm{C}$. 

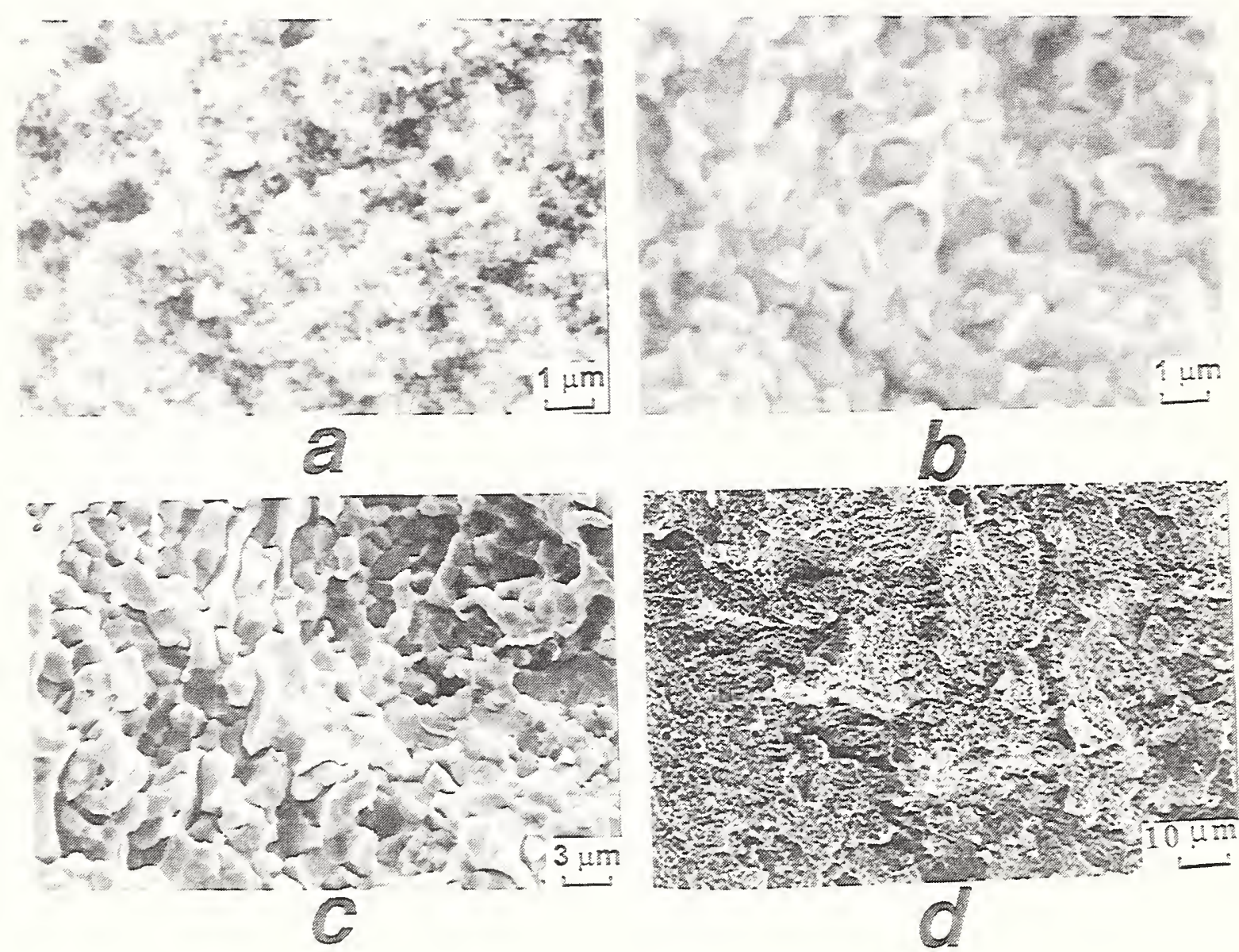

Figure 10. Fracture surfaces of $\mathrm{NN}$ after sintering at (a) $580^{\circ} \mathrm{C}$, (b) $700^{\circ} \mathrm{C}$, (c) $965^{\circ} \mathrm{C}$, or (d) HIPing at $500^{\circ} \mathrm{C}$. 

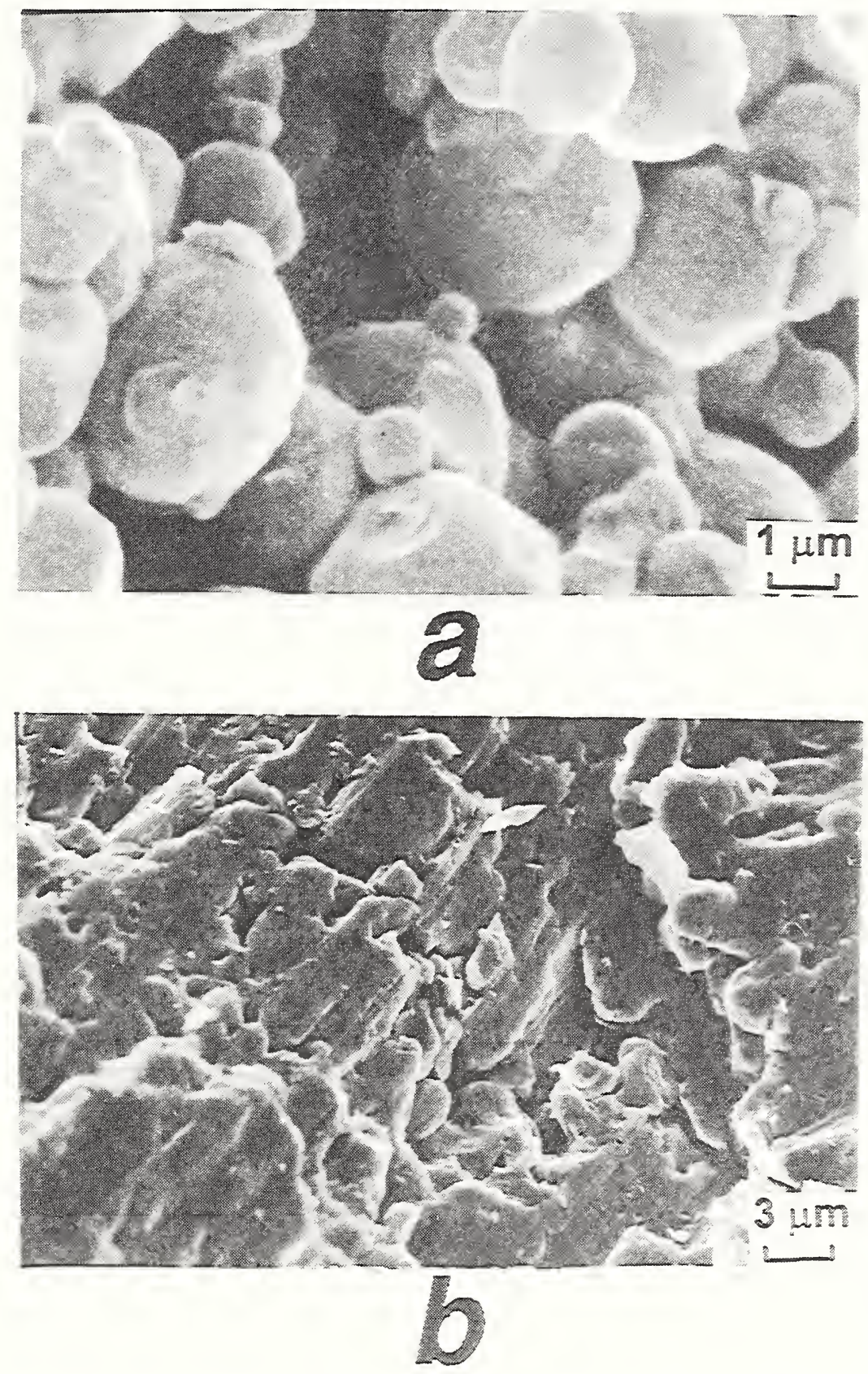

Figure 11. Fracture surfaces of MM(a) after sintering at (a) $580^{\circ} \mathrm{C}$ and (b) $700^{\circ} \mathrm{C}$. 


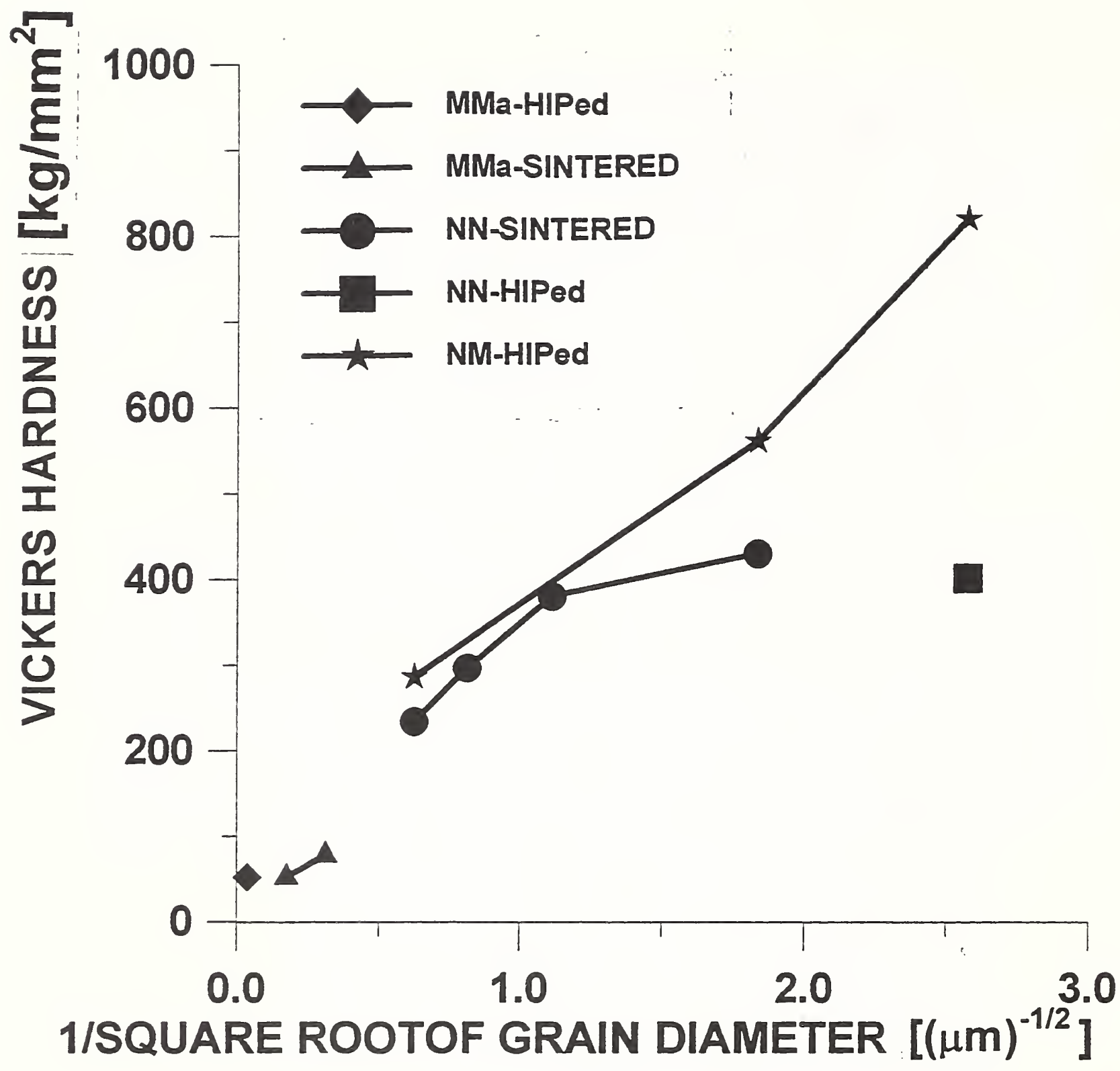

Figure 12. Hardness of iron as a function of grain size. 


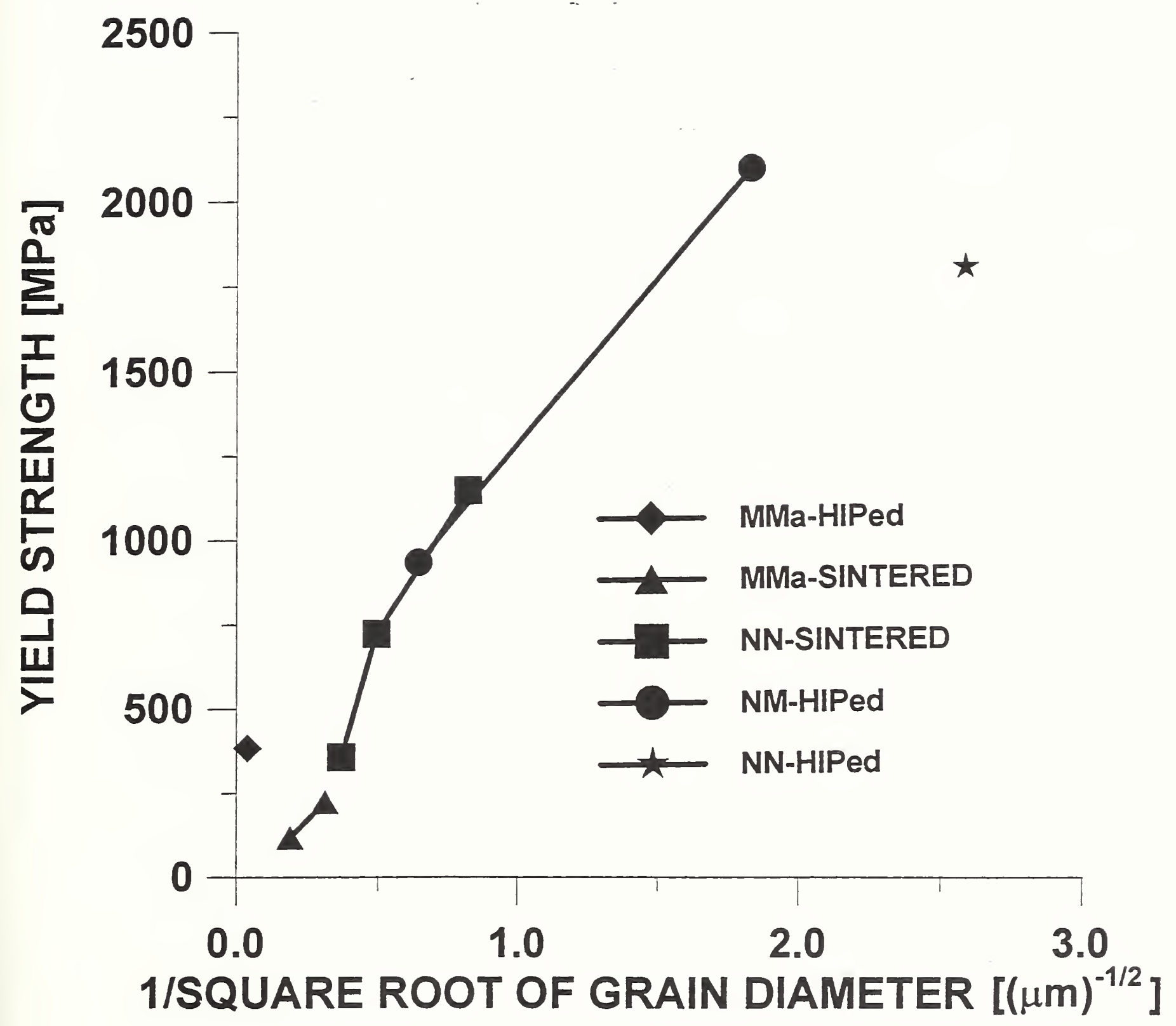

Figure 13. Yield strength of iron as a function of grain size. 


